\title{
Pain measurement in the elderly: evaluation of psychometric properties of the Geriatric Pain Measure - Portuguese version*
}

\author{
Mensuração da dor em idosos: avaliação das propriedades psicométricas da versão em \\ português do Geriatric Pain Measure
}

Thaisa Segura da Motta1, Regina Clara Gambaro', Fânia Cristina Santos²
${ }^{*}$ Received from the Discipline of Geriatrics and Gerontology, Federal University of São Paulo, SP, Brazil.

DOI 10.5935/1806-0013.20150026

\section{ABSTRACT}

BACKGROUND AND OBJECTIVES: The "Geriatric Pain Measure" was developed for multidimensional pain evaluation in the elderly, being easy to apply and understand. It has already been translated and transculturally adapted to Brazil (Geriatric Pain Measure-P). This study aimed at evaluating its psychometric properties, checking whether they are adequate.

METHODS: Participated in the study 70 community elderly, aged 60 years or above, of both genders, with chronic pain (three months or longer), with intensity equal to or higher than $30 \mathrm{~mm}$ according to the pain visual analog scale. Socio-demographic characteristics, pain duration and intensity were evaluated. For reliability and validity, two interviewers have applied the Geriatric Pain Measure and, in up to 14 days, a single interviewer has reapplied it. For validity, the Geriatric Pain Measure-P "Total Adjusted Score" and its questions related to pain intensity (Q 19 and 20) were correlated to the visual analog scale and, in a subsample, the Geriatric Pain Measure-P "Total Adjusted Score" was correlated to daily life functionality.

RESULTS: Sample was made up especially of long-lived elderly females, widows, with low education and moderate to severe pain. Internal consistency was adequate (Cronbach's alpha $=0.729$ ) and reproducibility was satisfactory (low variability without statistically significant differences). The Geriatric Pain Measure-P "Total Adjusted Score" and the visual analog scale had low correlation but it was regular for Q19 and Q20 of the Geriatric Pain Measure-P and for the visual analog scale (19 $\mathrm{r}=45.5 \%, 20 \mathrm{r}=51.9 \%$; $\mathrm{p}<0.05)$.

1. Federal University of São Paulo, Discipline of Geriatrics and Gerontology, São Paulo, SP, Brazil.

2. Federal University of Săo Paulo, Service of Pain and Musculoskeletal Diseases, Discipline of Geriatrics and Gerontology, São Paulo, SP, Brazil.

Submitted in December 14, 2014.

Accepted for publication in May 20, 2015.

Conflict of interests: none - Sponsoring sources: none.

Correspondence to:

Thaisa Segura da Motta

Rua Francisco de Castro, 105 - Vila Clementino

04044-000 São Paulo, SP, Brasil.

E-mail: thamotta@hotmail.com

(C) Sociedade Brasileira para o Estudo da Dor
CONCLUSION: The Geriatric Pain Measure-P had its psychometric properties analyzed and adequate reliability and validity were found. It was easy to apply and understand, demanding a short period of time.

Keywords: Elderly, Geriatric Pain Measure, Pain evaluation, Psychometric properties, Validation.

\section{RESUMO}

JUSTIFICATIVA E OBJETIVOS: O "GeriatricPainMeasure" foi desenvolvido para avaliação multidimensional da dor em idosos, sendo de fácil aplicabilidade e compreensão. Já foi traduzido e adaptado transculturalmente para o Brasil (GeriatricPainMeasure-P). O objetivo deste estudo foi estudar suas propriedades psicométricas, verificando se são adequadas.

MÉTODOS: Foram avaliados 70 idosos da comunidade, com 60 anos ou mais, de ambos os gêneros, com dor crônica (três meses ou mais), de intensidade maior ou igual a $30 \mathrm{~mm}$ segundo a escala analógica visual de dor. Foram apuradas as características sócio-demográficas, intensidade e duração da dor. Para as propriedades confiabilidade e validade, dois entrevistadores aplicaram o Geriatric Pain Measure e, em até 14 dias, apenas um entrevistador o reaplicou. Para a validade, o Geriatric Pain Measure- $P$ "Escore Total Ajustado" e suas questôes relacionadas à intensidade dolorosa (Q19 e 20) foram correlacionadas com escala analógica visual, e ainda, numa subamostra, o Geriatric Pain Measure-P "Escore Total Ajustado" foi correlacionado com funcionalidade na vida diária.

RESULTADOS: A amostra foi composta principalmente por idosas longevas, viúvas, de baixa escolaridade e com dor de intensidade moderada a intensa. A consistência interna foi adequada (alfa de Cronbach=0,729) e a reprodutibilidade satisfatória (variabilidade baixa e sem diferenças estatisticamente significativas). O Geriatric Pain Measure-P "Escore Total Ajustado" e a escala analógica visual apresentaram baixa correlação, mas a mesma foi regular para Q19 e Q20 do Geriatric Pain Measure-P e para a escala analógica visual (19 r=45,5\%, $20 \mathrm{r}=51,9 \%$; $\mathrm{p}<0,05)$.

CONCLUSÁO: O Geriatric Pain Measure-P teve propriedades psicométricas analisadas, sendo apuradas confiabilidade e validade adequadas. Foi de fácil aplicabilidade e compreensão, demandando curto período de tempo.

Descritores: Avaliação de dor, Geriatric Pain Measure, Idosos, Propriedades psicométricas, Validação. 


\section{INTRODUCTION}

Most elderly population suffers of chronic pain, being that its prevalence among community elderly may vary from 25 to $50 \%$, in some studies ${ }^{1-4}$. Chronic pain is multifactorial and its control may be difficult due to the complex interaction of its various domains (physical, psychological and social) with other related factors. Nevertheless, such interaction varies not only among individuals, but also along time for a same individual ${ }^{5}$.

Notwithstanding the high prevalence of chronic pain among the elderly, its implications for their health and quality of life are inadequately studied, evaluated and managed ${ }^{2}$. Subjective concepts and phenomena, such as pain, are difficult to be accurately measured without the aid of tools which, in their vast majority, are validated for specific populations such as youngsters.

One-dimension pain evaluation tools often measure its intensity, being the most common the visual analog scale (VAS) and the pain verbal numeric scale (VNS). On the other hand, multidimensional tools, such as McGill Pain Questionnaire and The Wisconsin Pain Inventory, which address pain in its different domains, are long and difficult to score and to apply to the elderly ${ }^{6}$. The practical guide for chronic pain in the elderly, developed and updated by the American Society of Geriatrics (1998 and 2002)7,8 recommends that multidimensional tools should be used to evaluate pain in the elderly. So, there is the need for tools allowing pain quantification and approach in the elderly in a multidimensional manner, and that they are culturally adapted for countries with languages different from English.

There are not many specific tools in Brazil that are easy to be clinically applied for multidimensional pain evaluation in the elderly. The Geriatric Pain Measure (GPM) ${ }^{9}$ was developed to provide multidimensional pain evaluation, being easy to apply and understand, which may be useful for outpatient elderly populations or those living in long term care facilities. It has already been translated and culturally adapted for Brazil $(\mathrm{GPM}-\mathrm{P})^{10}$, however its psychometric properties have not yet been studied in our country.

GPM addresses pain multidimensions, such as intensity (items 13, 17, 19, 20-23), "disengagement" (items 9-12, 15, $18,24)$, pain at ambulation (items 4-7), pain at vigorous activities (items 1-3) and pain during other activities (items $8,13-16)^{9}$, involving sensory-discriminating, motivational-affective and cognitive-evaluative dimensions of pain, described by Melzack $\& \mathrm{Katz}^{11}$.

This study aimed at evaluating, in chronic pain elderly patients, psychometric measures of GPM-P, that is, at confirming its reliability, by means of internal consistency and reproducibility and also its validation by means of its construct validity.

\section{METHODS}

This is an epidemiologic, observational, descriptive and analytical study. Participated in the study 70 elderly, from
September 01 to 30, 2014, who were been followed by the "Service of Pain and Musculoskeletal Diseases", Discipline of Geriatrics and Gerontology/DIGG - Federal University of São Paulo/UNIFESP.

Inclusion criteria were elderly aged 60 years or above, of both genders, with chronic pain lasting for more than three months and intensity above $30 \mathrm{~mm}$ by VAS. Exclusion criteria were those with chronic uncompensated diseases, unable to walk or verbally communicate, needing immediate anesthetic treatment at the judgment of the assistant physician, and with cancer pain. All participants have signed the Free and Informed Consent Term (FICT).

Socio-demographic data (age, gender, marital status, race, education level) and chronic pain-related data, such as duration and pain intensity measured by VAS were collected. VAS is a tool measuring pain intensity, which varies from no pain $(0 \mathrm{~mm})$ or the worst possible pain $(100 \mathrm{~mm})$, being mild pain from 0 to $3 \mathrm{~mm}$, moderate pain from 31 to $70 \mathrm{~mm}$ and severe pain above $70 \mathrm{~mm}^{12}$.

GPM-P (Attachment 1) was then applied. It has a total score obtained by the sum of scores of its items, which varies from "zero pain" (total 0) to "severe pain" (total 42), being adjusted for total score with variation from 0 to 100 (total adjusted score) when the sum of final scores is multiplied by 2.38. Total adjusted score allows the classification of pain as mild, for scores varying from 0-30, moderate for scores from 30-69 and severe for scores above 70. The test was applied by two independent interviewers (E1 and E2) on the same day. In a maximum period of 14 days, without any analgesic intervention, GPM-P was once more applied, now by just one interviewer (E1). Such procedure was adopted to study GPM-P psychometric properties. Tool reliability was obtained via its internal consistence and reproducibility; construct study was carried out for validity (construct validity).

There are different approaches to validate a tool. Face validity subjectively evaluates whether the tool measures what is intended to be measured (validity already given to GPM-P in its translation and cultural adaptation process) ${ }^{10}$; content validity evaluates whether tool components represent the dimension of what is intended to be measured (validity also already given to GPM-P) ${ }^{10}$; construct validity, one of the most important processes for tool validation, involves the comparison with commonly used clinical parameters. To get construct validity in this study, we have correlated GPM-P questions 19 and 20 (Q 19 and 20), pain-related categorical variables with pain VAS, as well as GPM-P "total adjusted score" correlations with VAS and also with functionality according to basic (BDLA) ${ }^{13}$ and instrumental (IDLA) ${ }^{14}$ activities, being that this latter correlation was observed in just one convenience subsample.

Two-proportion equality test was used to characterize relative frequency distribution of qualitative variables; Cronbach Alpha Coefficient was used for internal consistency; Paired Student $t$ test was used for reproducibility; and Intraclass Correlation Coefficient (ICC) was used for reliability. Pear- 
son Correlation was used for construct validity. Significance level was $5 \%$.

This study was approved by the Ethics Committee, Federal University of São Paulo (CEP 824,142/2014).

\section{RESULTS}

Our sample was made up of 70 elderly people, being that 19 of them have not attended the last interview. Reasons for absence were not obtained, notwithstanding the efforts to get them.

There has been frequent presence of long-lived (80 years old or above), females $(87.0 \%)$, Caucasian $(67.8 \%)$, widow/er $(53.8 \%)$ (Tables 1 and 2$)$. With regard to pain, most prevalent intensities according to VAS were moderate and severe, with mean duration of 10.77 years (Table 1 ).

Convenience subsample $(\mathrm{n}=37$ ) was primarily made up of female elderly, Caucasian, widows, low education level (1-4 years), functionally independent, with moderate pain with mean duration of 3 months to 1 year (Table 3 ).

GPM-P has demanded a short period to be applied, with mean time varying from 5 to 7 minutes.

With regard to internal consistency, according to Cronbach

Table 1. Socio-demographic characteristics and pain evaluation of the sample; quantitative variables

\begin{tabular}{|c|c|c|}
\hline Socio-demographic characteristics & $\mathrm{n}$ & $\%$ \\
\hline \multicolumn{3}{|l|}{ Age (years) } \\
\hline Mean ( $\left.{ }^{*} \mathrm{SD}\right)$ & & $82.91(6.81)$ \\
\hline${ }^{\star *}$ Min-Max & & $64-95$ \\
\hline $60-70$ & 3 & 6 \\
\hline $71-80$ & 13 & 24 \\
\hline $81-90$ & 33 & 61 \\
\hline$>90$ & 5 & 9 \\
\hline \multicolumn{3}{|l|}{ Education level (years) } \\
\hline Mean $\left({ }^{*} \mathrm{SD}\right)$ & & $4.84(3.91)$ \\
\hline${ }^{* *} \operatorname{Min}-$ Max & & $0-20$ \\
\hline Illiteracy & 9 & 13 \\
\hline Basic education (1-4) & 34 & 51 \\
\hline Elementary school (5-8) & 13 & 20 \\
\hline High school (9-11) & 9 & 13 \\
\hline College (>11) & 2 & 3 \\
\hline \multicolumn{3}{|l|}{ Pain intensity: visual analog scale $(\mathrm{mm})$} \\
\hline Mean $\left({ }^{*} \mathrm{SD}\right)$ & & $60.94(2.24)$ \\
\hline${ }^{\star \star}$ Min-Max & & $30-100$ \\
\hline Mild (0-30) & 7 & 10 \\
\hline Moderate $(31-70)$ & 31 & 44 \\
\hline Severe (71-100) & 32 & 46 \\
\hline \multicolumn{3}{|l|}{ Pain duration (years) } \\
\hline Mean $\left({ }^{*} \mathrm{SD}\right)$ & & $10.77(14.76)$ \\
\hline${ }^{*}$ Min-Max & & $0.25-60$ \\
\hline
\end{tabular}

Table 2. Socio-demographic characteristics of the sample; qualitative variables

\begin{tabular}{lccc}
\hline Socio-demographic characteristics & $\mathrm{n}$ & $\%$ & $\mathrm{p}$ value \\
\hline Marital status & 19 & 29.2 & 0.004 \\
Married & 4 & 6.2 & $<0.001$ \\
Separated & 35 & 53.8 & Ref. \\
Widow/er & 7 & 10.8 & $<0.001$ \\
Single & & & \\
Gender & 60 & 87.0 & $<0.001$ \\
Female & 9 & 13.0 & \\
Male & & & \\
Race & 40 & 67.8 & Ref. \\
Caucasian & 3 & 5.1 & $<0.001$ \\
African-Brazilian & 5 & 8.5 & $<0.001$ \\
Yellow & 11 & 18.6 & $<0.001$ \\
$\quad$ Mullato & & & \\
\hline
\end{tabular}

Table 3. Socio-demographic characteristics, pain and functionality evaluation of the subsample

\begin{tabular}{|c|c|c|}
\hline Variables & $\mathrm{n}$ & $\%$ \\
\hline \multicolumn{3}{|l|}{ Age (years) } \\
\hline $80-85$ & 11 & 30 \\
\hline $86-90$ & 21 & 57 \\
\hline $91-95$ & 5 & 13 \\
\hline \multicolumn{3}{|l|}{ Gender } \\
\hline Male & 6 & 16 \\
\hline Female & 32 & 84 \\
\hline \multicolumn{3}{|c|}{ Education level (years) } \\
\hline Illiteracy & 7 & 19 \\
\hline $1-4$ & 22 & 58 \\
\hline $5-8$ & 5 & 13 \\
\hline $9-11$ & 2 & 5 \\
\hline$>12$ & 2 & 5 \\
\hline \multicolumn{3}{|l|}{ Marital status } \\
\hline Widow (er) & 23 & 60 \\
\hline Single & 4 & 11 \\
\hline Married & 10 & 26 \\
\hline Separated & 1 & 3 \\
\hline \multicolumn{3}{|l|}{ Race } \\
\hline Caucasian & 21 & 58 \\
\hline Mullato & 10 & 26 \\
\hline Yellow & 5 & 13 \\
\hline African-Brazilian & 1 & 3 \\
\hline \multicolumn{3}{|l|}{ Pain duration (years) } \\
\hline $0.25-1$ & 10 & 28 \\
\hline $1-5$ & 9 & 25 \\
\hline $5-10$ & 4 & 11 \\
\hline $11-20$ & 5 & 14 \\
\hline$>20$ & 8 & 22 \\
\hline
\end{tabular}


Table 3. Socio-demographic characteristics, pain and functionality evaluation of the subsample - continuation

\begin{tabular}{lcc}
\hline Variables & $\mathrm{n}$ & $\%$ \\
\hline Pain intensity: VAS (mm) & 7 & 19 \\
Mild (0-30) & 18 & 47 \\
Moderate (31-70) & 13 & 34 \\
Severe (71-100) & & \\
IDLA & 17 & 46 \\
$26-27$ & 13 & 35 \\
$21-25$ & 6 & 16 \\
$16-20$ & 1 & 3 \\
$10-15$ & 0 & 0 \\
9 & & \\
BDLA & 35 & 95 \\
5 \& 6 & 2 & 5 \\
3 \& 4 & 0 & 0 \\
1 \& 2 & & \\
\hline I & instrumental daily life activity; BDLA & basic daily life activity.
\end{tabular}

Alpha Coefficient, values for all interviews were very good (above 0.6) (Table 4).

There has been $<50 \%$ Variation Coefficient when reproducibility was evaluated, which has shown low variability of results and, as a consequence, their homogeneity (Table 5). There has been no statistically significant difference be-

Table 4. Internal Geriatric Pain Measure-P consistency according to Cronbach Alpha Coefficient

\begin{tabular}{lc}
\hline & Cronbach Alpha \\
\hline E1 & 0.729 \\
E2 & 0.791 \\
E1 final interview & 0.727 \\
\hline
\end{tabular}

$\mathrm{E} 1$ = interview 1; E2 = interview 2; E1 final interview = final interview by observer 1.

Table 5. Geriatric Pain Measure-P Reproducibility

\begin{tabular}{|c|c|c|c|c|}
\hline GPM-P "total adjusted score" & \multicolumn{2}{|c|}{ E1 } & E2 & $\begin{array}{c}\text { E1 final } \\
\text { interview }\end{array}$ \\
\hline $\mathrm{n}$ & \multicolumn{2}{|c|}{$(70)$} & (70) & $(51)$ \\
\hline Mean & \multicolumn{2}{|c|}{56.36} & 56.62 & 52.97 \\
\hline Median & \multicolumn{2}{|c|}{52.4} & 55.9 & 50.0 \\
\hline Standard deviation & \multicolumn{2}{|c|}{18.37} & 19.23 & 17.92 \\
\hline Variation coefficient (\%) & \multicolumn{2}{|c|}{33} & 34 & 34 \\
\hline Minimum values & \multicolumn{2}{|c|}{14.3} & 19.0 & 19.0 \\
\hline Maximum values & \multicolumn{2}{|c|}{100.0} & 97.6 & 95.2 \\
\hline \multirow[t]{2}{*}{ Confidence interval } & \multicolumn{2}{|c|}{4.30} & 4.50 & 4.92 \\
\hline & $E 1(p)$ & E2 (p) & & \\
\hline E2 & 0.759 & & & \\
\hline E1 final interview & 0.427 & 0.167 & & \\
\hline
\end{tabular}

$\overline{\mathrm{E} 1}$ = interview 1; E2 = interview 2; E1 final interview = final interview by observer 1. tween observers (E1 and E2) and intra-observer (E1 and E1 final interview). So, GPM-P has shown good reproducibility (Table 5).

GPM-P "total adjusted score" had low correlation with pain intensity by VAS, because there has been variation coefficient ("r") between 20 and 40\% ("r"=25.2\%; p=0.035) (Table 6). According to ICC, the correlation between GPM-P "total adjusted score" and pain intensity by VAS was not statistically significant. However, considering GPM-P Q19 and Q20 and VAS, there have been higher and statistically significant correlations ( $45.5 \%$ and $51.9 \%$, respectively) (Table 6). So, after analyzing GPM-P construct validity, there have been correlations classified as regular (" $r$ " between 40 and 60\%) and, in this case, for being positive correlations, the higher the pain by VAS, the higher GPM-P Q19 and Q20 scores.

Table 6. Construct validity: correlation among variables "Geriatric Pain Measure-P Total Adjusted Score", Q19 and Q20 and the visual analog scale

\begin{tabular}{lcc}
\hline & VAS & p value \\
\hline GPM-P "total adjusted score" & $25.2 \%$ & 0.035 \\
Q19 (E1) & $45.5 \%$ & $<0.001$ \\
Q20 (E1) & $51.9 \%$ & $<0.001$ \\
\hline
\end{tabular}

Q19 (E1) = GPM-P question 19 of examiner 1; Q20 (E1): GPM-P question 20 of examiner 1 ; VAS = visual analog scale.

There have been no significant correlations between GPM-P "Total Adjusted Score" and functionality, considering IDLA and BDLA ( $\mathrm{p}=0.054$ and $\mathrm{p}=0.185$, respectively.

\section{DISCUSSION}

This study had a higher number of long-lived elderly people, which is the population growing the most worldwide ${ }^{15}$. We have also observed a higher prevalence of females ( $87 \%$ of total sample and $84 \%$ of subsample), in line with the literature which points to a feminization of aging, even among longlived elderly people ${ }^{16}$. A Sweden study has observed that pain prevalence peak is around 65 years of age, decreasing among long-lived elderly ( 75 to 84 years old or above) ${ }^{17}$, but this was not observed in our sample. However, pain detection among the elderly may be difficult because many of them do not report pain for considering it a normal aging consequence ${ }^{18,19}$. Our sample, although small, has not limited the analysis of results. Not all patients attended the final interview (approximately $73 \%$ of total sample); however it is worth mentioning that pain might have limited their attendance since very often they live far away or need third parties to take them to consultations.

It was observed that the studied tool, GPM-P, was easy to be understood by the elderly, demanding a short period for its application ( 5 to 7 minutes). By studying its measurement properties, as to internal consistency, scores were very good with "Cronbach Alpha Coefficient" considered high (above 0.70) for all interviews (E1, E2 and E1 final interview). Lit- 
erature has shown high original GPM internal consistency $(\alpha=0.9445)^{9}$ and of its translated versions, such as the European version $(\alpha=0.91)^{20}$ and the Korean version $(\alpha=0.92)^{21}$. Cronbach alpha coefficient scores are considered adequate when above 0.60; however Kline ${ }^{22}$ considers minimally acceptable scores above 0.70 .

Reproducibility has also shown to be adequate. Such property should be tested by more than one evaluator (interobserver) and by a same evaluator (intra-observer) to get "repeatability" of the method. Our study has shown low correlation between GPM-P "total adjusted score" and pain intensity by VAS, but one should note that pain VAS, which is a one-dimension tool, was used in this study. We decided not to use a "golden standard" multidimensional tool, which was a limitation of our study, because in Brazil there is no easy-to-apply questionnaire for multidimensional pain evaluation, especially among the elderly. McGill Questionnaire $^{6}$, not specifically developed for the elderly, has been already validated in Brazil, including validation on elderly samples; however this tool has been already widely used with DIGG/UNIFESP patients, being observed major understanding difficulties among these patients. Moreover, several limitations for its geriatric use have been described, such as difficulty to be understood by the elderly, by people with low education levels and with concentration difficulties. So, this study decided to use pain VAS alone.

GPM-P questions quantitatively addressing pain intensity (Q19 regarding pain intensity the day of the interview and Q20 related to pain in the last seven days) were correlated to VAS for construct validity and there has been a correlation classified as regular. It is known that the application of visual analog tools for the elderly, such as VAS, is not free from problems. According to Gagliese \& Melzack ${ }^{23}$, approximately $30 \%$ of the elderly without cognitive deficits may be unable to complete this type of scale. Also for construct validity, GPM-P "total adjusted score" was correlated to functionality but there has been no significant correlation. So, GPM-P was unable to show association between pain intensity and functionality among evaluated elderly individuals.

Literature review shows increased interest in studying aging and its consequences. Chronic pain among the elderly is very important for clinical practice because it may determine noxious consequences varying from mobility impairment to the favoring of falls, which put at risk the independence and also the lives of the elderly.

\section{CONCLUSION}

In our study, GPM-P measurement properties were analyzed and it was shown to be reliable and valid for multidimensional pain evaluation among the elderly. It was also observed that it is an easy and fast tool to be applied, in addition to being well understood by the elderly. Studies with larger samples may contribute to reinforce the validity of this tool.
Attachment 1. "GeriatricPainMeasure" Questionnaire - Portuguese version $^{10}$

\begin{tabular}{l}
\hline Name: \\
Please, answer each question checking yes Answer \\
or no \\
1- Do you have or believe you would have ( ) No ( ) Yes \\
pain with intensive activities such as: run- \\
ning, lifting heavy objects, or participating in \\
activities requiring physical effort? \\
2- Do you have or believe you would have ( ) No ( ) Yes \\
pain with moderate activities such as moving \\
a heavy table, using vacuum cleaner, walking \\
or playing with a ball? \\
3- Do you have or believe you would have ( ) No ( ) Yes \\
pain when you lift or carry a shopping bag? \\
4- Do you have or believe you would have ( ) No ( ) Yes \\
pain if you climbed a flight of stairs? \\
5- Do you have or believe you would have ( ) No ( ) Yes \\
pain if you climbed just some steps of a stair? \\
6- Do you have or would have pain when you ( ) No ( ) Yes \\
walk for more than one block? \\
7- Do you have or would have pain when you ( ) No ( ) Yes \\
walk for a block or less? \\
8- Do you have or would have pain when you ( ) No ( ) Yes \\
bathe or dress yourself?
\end{tabular}

9- Have you stopped working or performing ( ) No ( ) Yes activities due to pain?

10- Have you stopped doing something you ( ) No ( ) Yes like due to pain?

11- Have you decreased the type of work or ( ) No ( ) Yes other activities you perform due to pain?

12- Have your work or other activities ever ( ) No ( ) Yes required lots of effort due to pain?

13- Do you have sleep problems due to pain? ( ) No ( ) Yes 14- Does pain prevent you of participating in ( ) No ( ) Yes religious activities?

15- Does pain prevent you of participating in ( ) No ( ) Yes any other social or leisure activity (different from religious services)?

16- Does pain prevent or would prevent you ( ) No ( ) Yes from traveling or using common means of transportation?

17- Do you feel fatigue or tiredness due to ( ) No ( ) Yes pain?

18- Do you depend on someone else to help ( ) No ( ) Yes you due to pain?

19- From 0 to 10 , with zero meaning no pain $(0-10)$ and 10 meaning the worst imaginable pain, how is your pain today? 012345678910

20 - In the last seven days, on a scale from $(0-10)$ zero to ten, with zero meaning no pain and 10 meaning the worst imaginable pain, indicate your mean pain intensity? 012345678910

21- Do you have pain that never disappears? ( ) No ( ) Yes 22- Do you have pain every day? ( ) No ( ) Yes 23- Do you have pain several times a week? ( ) No ( ) Yes 24- Did pain make you feel sad or depressive ( ) No ( ) Yes in the last seven days?

Scoring - Give one point to every "Yes" and add numeric answers

Total scoring (0-42) ___ Adjusted scoring (total scoring $\times 2.38)(0-100)$ 


\section{REFERENCES}

1. Ferrell BA. Pain management in elderly people. J Am Geriatr Soc. 1991;39(1):64-73.

2. Ferrell BA. Pain. In: Osterweil D, Brummel-Smith K, Beck JC, (editors). Comprehensive Geriatric Assessment. New York: Mcgraw Hill; 2000. 381-97p.

3. Crook J, Rideout E, Browne G. The prevalence of pain complaints in a general population. Pain. 1984;18(3):299-314.

4. Thomas E, Peat G, Harris L, Wilkie R and Croft PR. The prevalence of pain and pain interference in a general population of older adults: cross-sectional findings from the North Staffordshire Osteoarthritis Project (NorStOP). Pain 2004; 110 (1-2): 361-368.

5. Cooner E, Amorosi S. The Study of Pain in Older Americans. New York: Louis Harris and Associates, 1997.

6. Pimenta CA, Teixeira MJ. Questionário de dor McGill: proposta de adaptaçáo para a língua portuguesa. Rev Esc Enf USP. 1996;30(3):473-83.

7. The management of chronic pain in older persons. AGS Panel on Chronic Pain in Older Persons. American Geriatric Society. J Am Geriatr Soc. 1998;46(5):635-51. Erratum in: J Am Gerriatr Soc. 1998.46(7):913.

8. The management of persistent pain in older persons AGS Panel on Persistent Pain in Older Persons. J Am Geriatr Soc. 2002;50(Suppl 6):S205-24.

9. Ferrell BA, Stein WM, Beck JC. The Geriatric Pain Measure: validity, reliability and factor analysis. J Am Geriatr Soc. 2000;48(12):1669-73.

10. Gambaro RC, Santos FC, Thé KB, Castro LA, Cendoroglo MS. Avaliação de dor no idoso: proposta de adaptaçấo do "Geriatric Pain Measure" para a língua portuguesa. Rev Bras Med (Rio de Janeiro) 2009;66(1):62-5.

11. Melzack R, Katz R. Pain measurement in persons in pain. In: Wall PD, Melzack R (editors) Textbook of Pain. Edinburgh: Churchill Livingstone; 1999. 409-26p.

12. Bodian CA, Freedman G, Hossain S, Eisenkraft JB, Beilin Y. The visual analog scale for pain: clinical significance in postoperative patients. Anesthesiology. 2001;95(6):1356-61.

13. Katz $S$, Akpom CA. A measure of primary sociobiological functions. Int J Health Serv 1976;6(3):493-508

14. Graf C. The Lawton instrumental activities of daily living scale. Medsurg Nurs. 2009;18(5):315-6

15. Kirkwood TB. A systematic look at an old problem: as life expectancy increases, a systems-biology approach is needed to ensure that we have a healthy old age. Nature. 2008;451(7):644-7.

16. Instituto Brasileiro de Geografia e Estatística (IBGE) [homepage na Internet]. Projeçáo da populaçấo do Brasil por sexo e idade - 1980-2050. Revisão 2008. Rio de Janeiro: IBGE - DEPIS. Disponível em: www.ibge.gov.br. Acesso em 01 fevereiro 2014.

17. Brattberg G, Parker MG, Thorslund M. The prevalence of pain among the oldest old in Sweden. Pain. 1996;67(1):29-34.

18. Celich KL, Galon C. Dor crônica em idosos e a sua influência nas atividades da vida diária e convivência social. Rev Bras Geriatr Gerontol. 2009;12(3):345-59.

19. Teixeira MJ, Teixeira WG, Santos FP. Epidemiologia clínica da dor músculo-esquelética. Rev Med. 2001;80(Ed Esp pt 1):1-21

20. Clough-Gorr KM, Blozik E, Gillmann G, Beck JC, Ferrell BA, Anders J, et al. The self-administered 24-item geriatric pain measure (GPM-24-SA): psychometric properties in three European populations of community-dwelling older adults. Pain Med. 2008;9(6):695-709.

21. Park J, Cho B, Paek Y, Kwon H, Yoo S. Development of a pain assessment tool for the older adults in Korea: the validity and reliability of a Korean version of the geriatric pain measure (GPM-K). Arch Gerontol Geriatr. 2009;49(2):199-203.

22. Kline P. A handbook of test construction: Introduction to psychometric design. London; UK: Methuen; 1986.

23. Gagliese L, Melzack R. Age differences in the quality of chronic pain: a preliminary study. Pain Res Manag. 1997;2(3):157-62. 